\title{
REVIEW
}

\section{Treatment of severe proliferative lupus nephritis: the current state}

\section{C Mok, R W S Wong, K N Lai}

Ann Rheum Dis 2003;62:799-804

Despite the development of new modalities, cyclophosphamide (CYC) remains the preferred initial treatment for severe proliferative lupus nephritis. Controversies continue about the best route, dosage, and duration of CYC treatment. For recalcitrant disease, new immunosuppressive and immunomodulating agents, immunoablative high dose CYC, nucleoside analogues, apheresis, and the biological response modifiers can be considered.

See end of article for authors' affiliations .....................

Correspondence to: Dr C C Mok, Department of Medicine, Tuen Mun Hospital, Tsing Chung Koon Road, New

Territories, Hong Kong,

China; ccmok@

netvigator.com

Accepted 5 March 2003
R enal disease is one of the most serious complications of systemic lupus erythematosus (SLE). Up to two thirds of patients with SLE have renal disease at some stage of their illness. Manifestations of lupus nephritis are protean, ranging from asymptomatic proteinuria to rapidly progressive crescentic glomerulonephritis. Of the various histological classes, diffuse proliferative glomerulonephritis (DPGN) (WHO class IV) carries the worst prognosis, resulting in $11-48 \%$ of patients with end stage renal disease at five years. ${ }^{1-6}$ The outcome is particularly bad for some ethnic groups such as the American black subjects. ${ }^{5}$ Focal proliferative glomerulonephritis (WHO class III) with $50 \%$ or more of the glomeruli affected has been shown to be prognostically similar to class IV disease and should be treated with equal vigour. ${ }^{78}$

Cyclophosphamide (CYC) has proven benefit in the long term preservation of renal function in severe lupus nephritis. CYC, given either orally or as intermittent pulses together with corticosteroid, has been evaluated in randomised controlled trials at the National Institutes of Health (NIH). ${ }^{9-13}$ These studies consistently showed that regimens containing CYC were better than corticosteroid alone in the preservation of renal function. Long term follow up (median 11 years) also indicated that pulse CYC continued to have better efficacy than pulse methylprednisolone (MP) alone. ${ }^{13}$

$$
\begin{aligned}
& \text { "About one fifth of patients with } \\
& \text { proliferative lupus nephritis may not } \\
& \text { respond to CYC treatment" }
\end{aligned}
$$

Although CYC and corticosteroid is the standard initial treatment of severe proliferative lupus nephritis, the optimal route of CYC administration, dose, and duration of treatment is uncertain. Recent evidence seems to suggest that both the efficacy and toxicities of CYC may be related to the cumulative dose being administered. ${ }^{14-16}$ Although a lower dose and shorter course of CYC may limit toxicities, ${ }^{17}$ its long term efficacy in preserving renal function when compared with standard CYC regimens remains to be established. Renal flares are common after discontinuation of $\mathrm{CYC}^{18}$ and maintenance treatment after an initial CYC response is recommended. Depending on treatment regimens and definitions of remission, up to $22 \%$ of patients with proliferative lupus nephritis are refractory to CYC treatment. ${ }^{19}$ Immunoablative high dose CYC, with and without stem cell rescue, and combination of CYC with other modalities such as the nucleoside analogues, plasmapheresis, and the monoclonal antibodies are being explored. Other modalities such as cyclosporin A, mycophenolate mofetil, intravenous immunoglobulin and B cell tolerogen have also been added to the therapeutic armamentarium for severe proliferative lupus nephritis.

\section{CYC IN LUPUS NEPHRITIS}

A series of randomised controlled trials were conducted by the NIH group of investigators. ${ }^{9-13}$ In the first study, intravenous pulse CYC plus oral corticosteroid was shown to be significantly more efficacious than corticosteroid alone in the preservation of renal function beyond five years. An extended observation for four more years showed similar results. ${ }^{10}$ The benefits of CYC were particularly apparent in high risk patients who had more chronic histological changes on renal biopsy. In the second study, in addition to the demonstration of better efficacy of CYC than pulse MP alone, an extended course of pulse CYC (30 months) was associated with a significantly lower rate of renal relapses than a short course of pulse CYC (six months). ${ }^{11}$ The third study demonstrated the superiority of a combination of pulse MP and pulse CYC over pulse MP alone in the induction of remission. ${ }^{12}$ Long term observation suggested that pulse MP and CYC might be synergistic. ${ }^{13}$

Thus, corticosteroid plus an extended course of intravenous pulse CYC becomes the standard protocol for the initial treatment of aggressive lupus nephritis in many centres.

Abbreviations: AZA, azathioprine; CSA, cyclosporin A; CYC, cyclophosphamide; DPGN, diffuse proliferative glomerulonephritis; IVlg, intravenous immunoglobulin; MMF, mycophenolate mofetil; MP, methylprednisolone; $\mathrm{NIH}$, National Institutes of Health; SLE, systemic lupus erythematosus 


\section{ROUTES OF CYC AND DURATION OF TREATMENT}

Daily oral CYC and prednisone was originally used for treating severe lupus nephritis in the 1970s, and was shown to be more effective than prednisone alone. ${ }^{20-24}$ The demonstration of the superiority of intravenous pulse CYC over daily oral CYC in the NIH study ${ }^{9}$ and fewer side effects such as cystitis, amenorrhoea, and malignancy in the pulse regimen has rendered oral CYC out of favour

However, it is noteworthy that in the NIH study, the median duration of oral CYC treatment was 48 months at a daily dose of $1-4 \mathrm{mg} / \mathrm{kg} /$ day. Although a lower dose ( $1 \mathrm{mg} / \mathrm{kg} /$ day) was used in the combination arm (oral CYC + azathioprine (AZA)), the median duration of treatment was still as long as 4.3 years. An average patient would definitely have received a cumulative dose of more than $70 \mathrm{~g}$ of CYC. As recent evidence suggests that many of the side effects of CYC such as malignancy and ovarian failure are dose related, ${ }^{15}{ }^{25-27}$ it appears that the greater toxicities of the oral CYC regimens in the NIH study were contributed to by the higher cumulative doses rather than by the route of administration. Recent regimens consisting of a shorter course ( six months) and a lower daily dose ( $1-2 \mathrm{mg} / \mathrm{kg} /$ day) of oral CYC appear to be well tolerated, with a much lower reported incidence of toxicities such as cystitis and malignancy. ${ }^{1428-30}$

Whether daily oral CYC is more efficacious than intermittent pulse CYC in lupus nephritis is uncertain. In the NIH study, ${ }^{9}$ it appeared that intravenous pulse CYC was more effective than the oral CYC regimens in the preservation of renal function beyond five years. However, the difference was not statistically significant. Moreover, the result could not be extrapolated to DPGN as all histological classes of lupus nephritis were included in the trial. A recent study compared the outcome of two historical cohorts with lupus related DPGN treated with prednisone and either 12 intravenous pulses of CYC or six months' oral CYC ( $1-2 \mathrm{mg} / \mathrm{kg} /$ day) followed by AZA $(2 \mathrm{mg} / \mathrm{kg} /$ day $) .{ }^{14}$ It was shown that the oral CYC regimen had a trend of higher remission rate, fewer renal relapses, and lower risk of renal function deterioration when compared with the intravenous arm. This trend was evident at six months after treatment and persisted up to 24 months. Although long term data are still pending, this study suggests that an initial induction with a higher cumulative dose of CYC is associated with a higher remission rate and fewer relapses of nephritis.

"A higher remission rate of nephritis occurs with an initial higher cumulative dose of CYC"

The optimal duration of CYC treatment is again unclear. In the study of Boumpas et al an extended course of intravenous pulse CYC was associated with a significantly lower cumulative risk of renal relapses than a shorter course of CYC at 60 months of follow up $(55 \% v 10 \%, \mathrm{p}=0.006) .{ }^{11}$ There was also a trend towards a lower risk of creatinine doubling in the extended CYC arm. However, a longer course of CYC was associated with more side effects such as cervical dysplasia.

The Euro-Lupus Nephritis Trial was a multicentre randomised study comparing a higher dose intravenous CYC (eight standard pulses in 12 months) with a lower dose CYC regimen (six fortnightly pulses of $500 \mathrm{mg}$ ) for proliferative lupus nephritis. ${ }^{17}$ AZA (2 mg/kg/day) was used as maintenance after CYC was stopped in both arms. It was shown that no significantly higher probability of treatment failure and renal flares occurred in the lower dose regimen. Infective complications were fewer in the lower dose group, but statistical significance was not be reached. This study suggests that a shorter duration and lower dose of CYC induction, followed by AZA maintenance is an effective regimen for lupus nephritis, with toxicities reduced. However, as patients with different histological classes of lupus nephritis were recruited and most patients had relatively mild renal disease $(22 \%$ with renal impairment at entry), the results could not be extended to high risk patients such as those with DPGN or impaired renal function at entry. Secondly, the duration of CYC treatment in both arms was shorter than that employed in the NIH studies and the follow up period was relatively short (median 41 months). It remains to be seen whether the long term efficacy of these less intensive CYC regimens is equivalent to conventional doses and duration of CYC.

\section{NON-REMISSION AND RENAL FLARES}

Although intravenous pulse CYC is the standard regimen for severe lupus nephritis, a less favourable outcome was reported in some uncontrolled studies, with $30-50 \%$ of patients developing either doubling of creatinine or end stage renal failure within five years. ${ }^{31-35}$ In the study by Gourley et al, the cumulative remission rate at five years was $85 \%$ for monthly pulse MP and 12 pulses of CYC in 24 months. ${ }^{12}$ This illustrates that remission cannot be achieved in certain patients despite an extended course of pulse CYC. Non-remission of nephritis is a strong determinant for end stage renal disease. ${ }^{36}$ Thus, more effective regimens are needed, especially for high risk patients such as black subjects and those with high chronicity scores on renal biopsy. ${ }^{5} 6930$

\section{"A flare of nephritis after discontinuation of CYC is} common and maintenance treatment is recommended"

Flare of nephritis after discontinuation of CYC is fairly common. Recurrence of nephritis is associated with new immunological and inflammatory insults to the kidney, and cumulative damage will lead to deterioration of renal function. The relapse rate of nephritis after CYC treatment of diffuse proliferative lupus nephritis ranges from 10 to $66 \%$ in various studies, depending on the severity of nephritis on recruitment, treatment regimens, definition of relapse, and the duration of observation. ${ }^{1137-39}$ Ciruelo et al described a cumulative rate of renal relapses of $46 \%$ at 10 years in patients treated with corticosteroid and CYC (intravenous or oral) for a median of 31 months. ${ }^{37}$ Boumpas et al found that $27 \%$ of patients who were treated with prednisone and intravenous pulse CYC had a renal flare within five years of treatment. ${ }^{11}$ Moroni et al observed that $66 \%$ of their patients treated with corticosteroid and cytotoxic agents had nephritis relapse over a median follow up of 128 months. ${ }^{38}$ Ioannidis et al described a cumulative relapse rate of $50 \%$ at 80 months in patients with proliferative lupus nephritis who remitted after intravenous pulse CYC ${ }^{39}$ A recent study by Illei et al reported that $45 \%$ of patients who remitted completely or partially after intravenous MP, intravenous CYC, or a combination of both, had renal relapses after a mean follow up of 117 months. ${ }^{18}$

\section{MAINTENANCE TREATMENT}

As renal flares are fairly common after CYC is discontinued, maintenance treatment with a less toxic drug is needed. Long term AZA after an induction course of CYC was a possible strategy to prevent renal relapses. ${ }^{17}{ }^{28}{ }^{30}$ In a recent multicentre retrospective study of 174 patients with SLE related DPGN, it was shown that long term AZA ( $1-2 \mathrm{mg} / \mathrm{kg} /$ day) after successful CYC induction was associated with significantly fewer renal flares. ${ }^{40}$ Boletis et al compared the efficacy of monthly intravenous immunoglobulin (IVIg) with maintenance intermittent pulse CYC in 14 patients who had completed a six month course of pulse CYC for proliferative lupus nephritis. ${ }^{41}$ The relapse rate was similar in both arms after a period of 18 months. However, the power of the study was not sufficiently large to show a difference between the efficacy of immunoglobulin and intravenous CYC as maintenance treatment. 
An ongoing randomised controlled trial in 54 patients with proliferative lupus nephritis demonstrated that maintenance treatment with mycophenolate mofetil (MMF) (500-3000 $\mathrm{mg} /$ day) was more effective than either quarterly intravenous pulse CYC $\left(0.5-1.0 \mathrm{~g} / \mathrm{m}^{2}\right)$ or AZA $(0.5-3.0 \mathrm{mg} / \mathrm{kg} / \mathrm{day})$ in the prevention of renal flares after an initial successful induction treatment with four to seven pulses of CYC. ${ }^{42}$ At 42 months, the cumulative probability of renal relapse was higher for CYC $(43 \%)$ than for AZA (37\%; $p=0.21)$ or MMF $(8 \% ; p=0.03)$. MMF was associated with significantly lower rates of infection and admission to hospital than CYC.

\section{COMBINATION REGIMENS CONTAINING CYC}

Combination strategies to achieve a synergistic effect and reduce adverse events are being studied. The recent extended observation of the NIH study showed that pulse MP was synergistic with pulse CYC in the induction of remission and prevention of renal function deterioration without enhancing toxicities. $^{13}$ A combination of CYC and AZA has also been evaluated.9 ${ }^{2024}$ A meta-analysis reported that the CYC and AZA combination was more effective than prednisone alone in reducing end stage renal failure. ${ }^{43}$ The addition of AZA appeared to be CYC-sparing, with a lower daily dose of CYC required and hence fewer treatment related toxicities. ${ }^{9}$

\section{Nucleoside analogues}

Fludarabine is a purine nucleoside analogue with selective activity against both dividing and resting lymphocytes. Low dose fludarabine depletes both $\mathrm{B}$ cells and certain $\mathrm{T}$ cell subsets. It was effective and well tolerated in the treatment of refractory idiopathic and lupus membranous nephropathy. ${ }^{44} \mathrm{~A}$ phase I/II study combining fludarabine and monthly low dose oral pulse CYC in lupus nephritis is underway. ${ }^{19}$ Another nucleoside analogue, 2-chloro-2'-deoxyadenosine, has also been evaluated in patients with proliferative lupus glomerulonephritis. A phase I study has established the safety and efficacy of this agent in the treatment of 12 patients with SLE. ${ }^{45}$

\section{Plasmapheresis}

Plasmapheresis was proposed to improve the efficacy of CYC treatment of lupus nephritis. However, in a randomised trial, addition of plasmapheresis to a regimen of corticosteroid and oral CYC did not appear to improve significantly the clinical outcome of patients with severe lupus nephritis. ${ }^{46}$ A synchronised plasmapheresis regimen with high dose CYC was employed by some investigators. ${ }^{47-49}$ The idea was to remove the autoantibodies and stimulate a rebound of pathogenic B cell clones, which would then be depleted by the cytotoxic effect of pulse CYC. Despite early reports of success, ${ }^{47}$ recent randomised controlled trials have not shown apheresis-CYC to be better than pulse CYC alone in the treatment of lupus nephritis in the long run, although addition of apheresis was associated with a more rapid remission. ${ }^{48} 49$

\section{Anti-CD20 monoclonal antibody}

Rituximab is a chimeric mouse/human anti-CD20 monoclonal antibody that has been proved to be effective in depleting $\mathrm{B}$ cells in vivo. ${ }^{50}$ Rituximab has been used anecdotally in the treatment of life threatening SLE. ${ }^{51}$ An open study of six patients with active SLE who were resistant to immunosuppressive treatment (corticosteroid, CYC, AZA, cyclosporin A (CSA), MMF) showed improvement in disease activity in five patients who received a protocol consisting of high dose oral prednisolone, two infusions of rituximab, and two infusions of intravenous CYC. ${ }^{52}$ Depletion of CD 19 B cells lasted for 3-6 months but the change in anti-dsDNA titres was variable. Treatment was well tolerated with no adverse effects related to rituximab infusion reported.

\section{IMMUNOABLATIVE CYC TREATMENT}

Immunoablative high dose CYC has shown preliminary success in SLE. High dose CYC, with stem cell rescue, ablates the pathogenic and autoreactive immune cells in the bone marrow and has been shown to induce remission of SLE for a median of 25 months in seven patients..$^{53}$ Another study using a lower dose of CYC ( $50 \mathrm{mg} / \mathrm{kg} /$ day for four consecutive days), followed by granulocyte-colony stimulating factor stimulation for white cell count recovery but without stem cell rescue, has also demonstrated efficacy in seven patients with refractory and severe autoimmune diseases, including two patients with SLE. ${ }^{54}$ The outcome of 14 patients with SLE, in whom the same treatment protocol was used, was recently reported. ${ }^{55}$ Nine of the patients had corticosteroid resistant lupus nephritis, and seven patients achieved either a complete or partial response after a mean follow up of 27 months.

\section{ALTERNATIVE TREATMENTS}

For patients who are reluctant to receive CYC or who are intolerant or refractory to the drug, other treatments can be considered. These include AZA, CSA, MMF, immunoadsorption, IVIg, anti-CD40L monoclonal antibody, and LJP394.

\section{Azathioprine}

The efficacy of AZA in lupus nephritis was evaluated in the NIH study. Although CYC showed a trend towards better renal function preservation than AZA beyond five years, the difference was not statistically significant. Two pooled analyses of clinical trials in lupus nephritis did not show any significant difference in the efficacy of CYC and AZA for the preservation of renal function. ${ }^{43}{ }^{56}$ A recent retrospective study showed that the long term outcome of patients with diffuse proliferative lupus nephritis treated with AZA approached that of CYC. ${ }^{57}$ As CYC has become the standard regimen for severe lupus nephritis, further comparative studies between CYC and AZA are no longer available.

\section{Cyclosporin A}

Uncontrolled studies have reported the efficacy of CSA in the treatment of proliferative lupus nephritis, especially in those patients who were resistant to or dependent on corticosteroids. ${ }^{58}{ }^{59} \mathrm{In}$ a randomised controlled study comparing CSA with a combination of corticosteroid and oral CYC in paediatric patients with proliferative lupus nephritis, an equivalent short term efficacy was demonstrated in both treatment arms. ${ }^{60}$ No comparative trials between CYC and CSA in adult patients with SLE are available, making the evidence for the initial use of CSA in severe lupus nephritis less convincing. However, CSA is an option in patients who cannot tolerate other cytotoxic agents because of cytopenia. Flares of disease activity may occur when the drug is tapered or suddenly withdrawn because of intercurrent infection or nephrotoxicity. ${ }^{59} 60$

\section{Mycophenolate mofetil}

MMF is a new immunosuppressive agent increasingly used in SLE. ${ }^{61}$ Uncontrolled studies and case series have demonstrated the efficacy of MMF in the treatment of renal and non-renal lupus refractory to conventional cytotoxic agents. ${ }^{62-64} \mathrm{~A}$ randomised controlled trial performed to compare MMF with sequential oral CYC followed by AZA in proliferative lupus nephritis showed an equal efficacy of the regimens at 12 months, ${ }^{29}$ but extended follow up for 36 months revealed a higher rate of renal relapses in the MMF arm. ${ }^{65} \mathrm{MMF}$ has also been shown to be better than either AZA or quarterly pulse CYC as maintenance treatment after successful initial pulse CYC induction for proliferative nephritis. ${ }^{42}$ Although toxicities are lower with MMF, the lack of long term data to show an equivalent efficacy with conventional CYC regimens is a major 


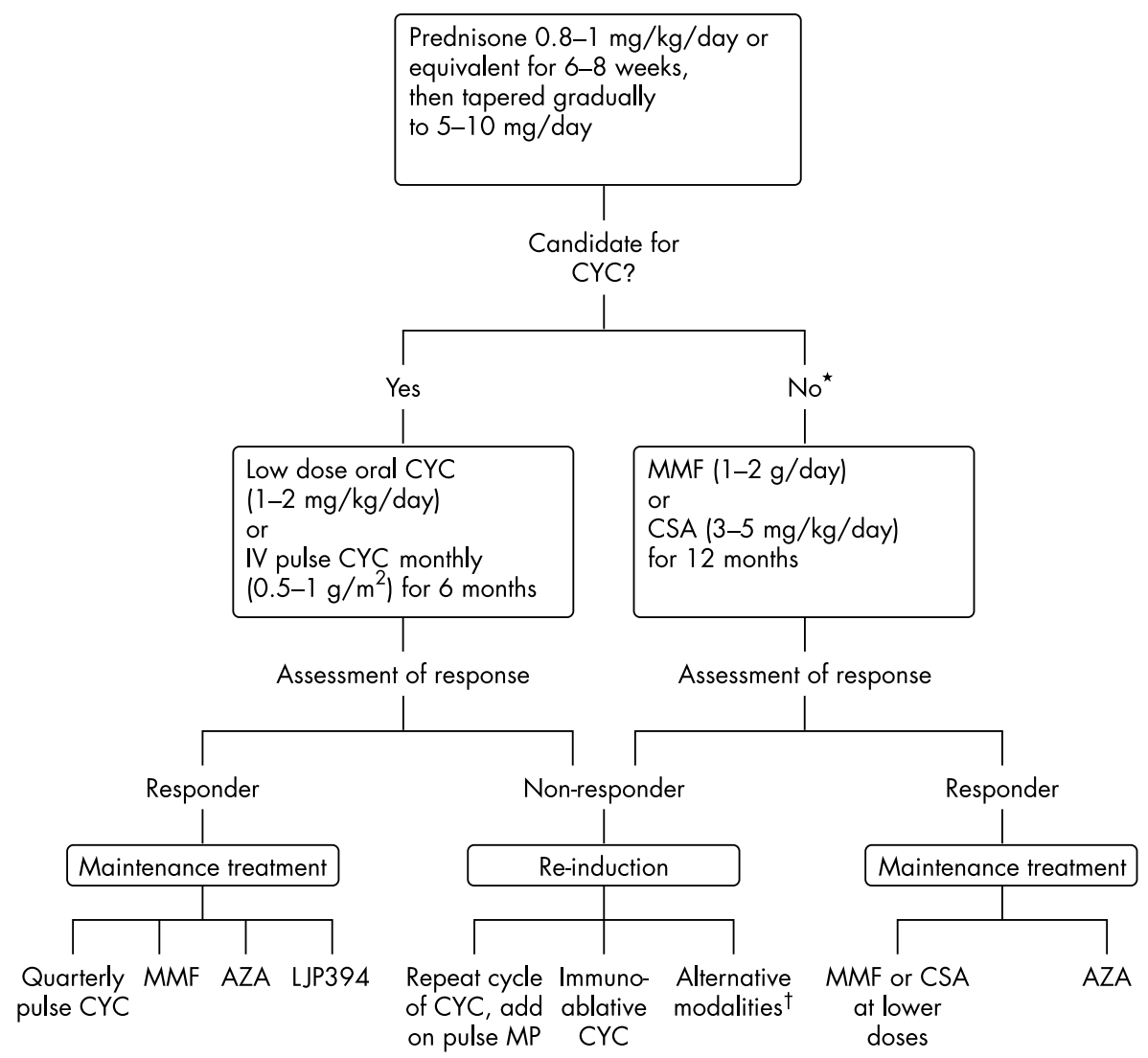

deterrent to its first line use in high risk patients. However, it is certainly a choice in patients with recalcitrant disease.

\section{Immunoadsorption}

Although plasmapheresis did not demonstrate additional benefits in severe lupus nephritis, immunoadsorption using staphylococcal protein A or Clq columns has been shown to be useful for refractory SLE in a small case series. ${ }^{667}$

\section{Intravenous immunoglobulin}

In a small trial IVIg was shown to be as effective as intravenous pulse CYC as maintenance treatment in proliferative lupus nephritis. ${ }^{41}$ IVIg has also been successfully used in patients with lupus nephritis resistant to conventional regimens. ${ }^{68}$ However, the high cost and the possibility of sucrose nephropathy are its major limitations.

\section{Blockade of costimulatory molecules}

Biological response modifiers, such as CTLA4-Ig and antiCD40L monoclonal antibodies, to block the interaction between T cells and B cells are being evaluated in SLE. ${ }^{21969}$ The interaction of B7 molecules on B cells and CD28 on T cells provides an important second costimulatory signal for $\mathrm{T}$ cell activation and production of antibodies by the B cells. A fusion protein consisting of CTLA4 and an immunoglobulin chain (CTLA4-Ig) binds B7 with a higher affinity than CD28 and inhibits B7/CD28 interaction. CTLA4-Ig has been shown to reduce autoantibody production, ameliorate glomerulonephritis, and prolong survival in murine lupus. ${ }^{70} \mathrm{~A}$ recent study showed that a combination of CYC and CTLA4-Ig was more effective than either agent alone in murine lupus nephritis. ${ }^{71}$

Another receptor-ligand pair, CD40 (on B cells) and CD40L or CD154 (on T cells), also provides an important costimulatory signal for $\mathrm{T}$ and $\mathrm{B}$ cell activation. Selective blockade of CD40L/CD40 interaction attenuates nephritis and improves survival of lupus-prone mice. ${ }^{72}$ A phase I trial demonstrated that IDEC-131, a humanised monoclonal antibody against disease. $^{74}$

\section{B cell tolerisation (LJP394)} underway. ${ }^{69} 78$

\section{Other newer modalities}

Figure 1 Treatment algorithm for severe proliferative lupus nephritis *Previous serious toxicities to CYC, severe cytopenia, patient's reluctance, etc. †Alternative treatments: MMF, CSA, immunoadsorption, apheresis, rituximab, IVlg.

CD40L, was safe and well tolerated in human SLE. ${ }^{73}$ However, a phase II randomised placebo controlled study did not show superiority of the agent over placebo at 20 weeks in 85 patients with active SLE, including $28 \%$ of patients with renal

LJP394 (abetimus sodium) consists of four 20-mer dsDNA epitopes conjugated to a non-immunogenic polyethylene glycol platform. It tolerises B cells by cross linking anti-dsDNA surface immunoglobulin receptor on the B cell and triggering the signal transduction pathways that lead to B cell anergy or apoptosis. ${ }^{75}$ A partially randomised placebo controlled study in 58 patients demonstrated a significant reduction of antidsDNA titres in patients receiving the highest dose of LJP394. ${ }^{76}$ The reduction in titres persisted for eight weeks after discontinuation of the drug. The incidence of adverse events was comparable in the placebo and active treatment groups.

A multicentred phase II/III trial on the efficacy of LJP394 in the prevention of renal flares in 230 patients with lupus nephritis (WHO class III, IV, or V) has just been completed ${ }^{77}$ It was demonstrated that in patients with high affinity of their serum IgG fraction for the DNA epitope of LJP394, treatment with the drug significantly reduced the number of renal flares, prolonged the time to renal flare, and was associated with fewer high dose immunosuppressive treatments at 76 weeks compared with placebo. LJP394 appeared to be well tolerated and adverse events were not significantly more common in the treatment group. An international phase III trial is

Other potential treatments for lupus nephritis include the anti-C5 complement monoclonal antibody, anti-interleukin 10 monoclonal antibody, anti-B lymphocyte stimulator and human recombinant DNAase. ${ }^{269} 78$ They are still in the preliminary stage of development. 


\section{ADJUNCTIVE TREATMENTS IN LUPUS NEPHRITIS}

Non-immune mechanisms such as hypertension and proteinuria are often implicated in the deterioration of renal function in patients with lupus nephritis. ${ }^{79}$ Thus, vigorous control of blood pressure and proteinuria is an important adjunctive measure in the management of lupus nephritis. Although angiotensin converting enzyme inhibitors have been shown to be anti-hypertensive, anti-proteinuric, and renoprotective in conditions such as idiopathic membranous nephropathy, ${ }^{80}$ they have not been properly evaluated in patients with lupus nephritis. Uncontrolled series suggested that they may be beneficial in patients with lupus nephritis with severe hypertension and proteinuria. ${ }^{81}{ }^{82}$ If proteinuria does not respond to salt restriction and angiotensin converting enzyme inhibition, the angiotensin II receptor antagonists may be considered..$^{83}$ Treatment of hyperlipidaemia after adequate control of proteinuria, blood pressure, and dietary fat intake may not alter renal progression but should be undertaken to offer protection against accelerated vascular disease. $^{79}$

\section{TREATMENT ALGORITHM}

Because of the limited reported information, there are no universal protocols for immunosuppressive treatment of severe proliferative lupus nephritis. The treatment plan has to be individualised according to the clinical situation, degree of activity and chronicity on renal histology, wishes and tolerability of the patients, and the presence of confounding variables such as intercurrent infection, severe cytopenias, and the presence of extrarenal disease. The principal goals of treatment are to induce remission of nephritis, prevent renal flares, and preserve renal function in the long run. These also have to be balanced against the risks of treatment related morbidities. Figure 1 outlines a suggested algorithm for the immunosuppressive treatment of severe proliferative lupus nephritis. This is by no means absolute, as different international experts would recommend different protocols.

\section{CONCLUSIONS}

The prognosis of lupus nephritis has improved significantly over the past few decades. This has been partly contributed to by a better understanding of the natural history of the disease, improved treatment regimens, and the use of adjunctive treatments. New treatments directed against more specific targets may theoretically be associated with higher efficacy and lower toxicity. It is hoped that more treatment options can be offered to patients with proliferative lupus nephritis in the near future, and the prognosis of the condition can continue to improve.

\section{Authors' affiliations}

C C Mok, Department of Medicine, Tuen Mun Hospital, Hong Kong, SAR, China

R W S Wong, K N Lai, Department of Medicine, Queen Mary Hospital, Hong Kong, SAR, China

\section{REFERENCES}

1 Cameron JS. Lupus nephritis. J Am Soc Nephrol 1999;10:413-24.

2 Zimmerman R, Radhakrishnan J, Valeri A, Appel G. Advances in the treatment of lupus nephritis. Annu Rev Med 2001;52:63-78.

3 Mok CC, Wong RWS, Lau CS. Lupus nephritis in southern Chinese patients: clinicopathological findings and long term outcome. Am J Kidney Dis 1999;34:315-23.

4 Yang LY, Chen WP, Lin CY. Lupus nephritis in children - a review of 167 patients. Pediatrics 1994;94:335-40.

5 Bakir AA, Levy PS, Dunea G. The prognosis of lupus nephritis in African-Americans: a retrospective analysis. Am J Kidney Dis 1994;24:159-71.

6 Dooley MA, Hogan S, Jennette C, Falk R. Cyclophosphamide therapy for lupus nephritis: poor renal survival in black Americans. Glomerular Disease Collaborative Network. Kidney Int 1997;51:1 188-95.
7 Lewis EJ, Schwartz MM, Korbet SM. Severe lupus nephritis: importance of re-evaluating the histologic classification and the approach to patient care. J Nephrol 2001;14:223-7.

8 Najafi CC, Korbet SM, Lewis EJ, Schwartz MM, Reichlin M, Evans J; The Lupus Nephritis Collaborative Study Group. Significance of histologic patterns of glomerular injury upon long-term prognosis in severe lupus patterns of glomerular injury upon long-term progn
glomerulonephritis. Kidney Int 2001;59:2156-63.

9 Austin HA III, Klippel JH, Balow JE, le Riche NGH, Steinberg AD, Plotz $\mathrm{PH}$, et al. Therapy of lupus nephritis: controlled trial of prednisone and cytotoxic drugs. N Engl J Med 1986:314:614-19.

10 Steinberg AD, Steinberg SC. Long-term preservation of renal functions in patients with lupus nephritis receiving treatment that includes cyclophosphamide versus those treated with prednisone only. Arthritis Rheum 1991;34:945-50.

11 Boumpas DT, Austin HA, Vaughn EM, Klippel JH, Steinberg AD, Yarboro $\mathrm{CH}$, et al. Controlled trial of pulse methylprednisolone versus two regimens of pulse CYC in severe lupus nephritis. Lancet 1992;340:741-5.

12 Gourley MF, Austin HA 3rd, Scott D, Yarboro CH, Vaughan EM, Muir J, et al. Methylprednisolone and cyclophosphamide, alone or in combination, in patients with lupus nephritis. A randomized, controlled trial. Ann Intern Med 1996;125:549-57.

13 Illei GG, Austin HA, Crane M, Collins L, Gourley MF, Yarboro CH, et al. Combination therapy with pulse cyclophosphamide plus pulse methylprednisolone improves long-term renal outcome without adding toxicity in patients with lupus nephritis. Ann Intern Med 2001;135:248-57.

14 Mok CC, Ho CTK, Siu YP, Chan KW, Kwan TH, Lau CS, et al. Treatmen of diffuse proliferative lupus glomerulonephritis: a comparison of two cyclophosphamide-containing regimens. Am J Kidney Dis 2001;38:256-64

15 Mok CC, Lau CS, Wong RWS. Risk factors for ovarian failure in patients with systemic lupus erythematosus receiving cyclophosphamide therapy. Arthritis Rheum 1998;41:831-7.

16 Houssiau FA, Jadoul M. Cytotoxic therapy of lupus nephritis: recent developments. Nephrol Dial Transplant 2002;17:955-7.

17 Houssiau FA, Vasconcelos C, D'Cruz D, Sebastiani GD, Garrido ER, Danieli $M G$, et al. Immunosuppressive therapy in lupus nephritis. The Euro-lupus Nephritis Trial, a randomized trial of low-dose versus high-dose intravenous cyclophosphamide. Arthritis Rheum 2002:46:2121-31.

18 Illei GG, Takada K, Parkin D, Austin HA, Crane M, Yarboro CH, et al. Renal flares are common in patients with severe proliferative lupus nephritis treated with pulse immunosuppressive therapy: long-term followup of a cohort of 145 patients participating in randomized controlled studies. Arthritis Rheum 2002;46:995-1002.

19 Takada K, Illei GG, Boumpas DT. Cyclophosphamide for the treatment of systemic lupus erythematosus. Lupus 2001;10:154-61

20 Ginzler E, Diamond H, Guttadauria M, Kaplan D. Prednisone and azathioprine compared to prednisone plus low dose azathioprine and cyclophosphamide in the treatment of diffuse lupus nephritis. Arthritis Rheum 1976; 19:693-9.

21 Donadio JV Jr, Holley KE, Ferguson RH, Ilstrup DM. Progressive lupus glomerulonephritis. Treatment with prednisone and combined prednisone and cyclophosphamide. Mayo Clin Proc 1976:51:484-94.

22 Donadio JV Jr, Holley KE, Ferguson RH, Ilstrup DM. Treatment of diffuse proliferative lupus nephritis with prednisone and combined prednisone and cyclophosphamide. N Eng J Med 1978;299:1151-5.

23 Steinberg AD, Decker JL. A double-blind controlled trial comparing cyclophosphamide, azathioprine and placebo in the treatment of lupus glomerulonephritis. Arthritis Rheum 1974;17:923-37.

24 Dinant HJ, Decker JL, Klippel JH, Balow JE, Plotz PH, Steinberg AD. Alternative modes of cyclophosphamide and azathioprine therapy in lupus nephritis. Ann Intern Med 1982;96:728-36.

25 Radis CD, Kahl LE, Baker GL, Wasko MC, Cash JM, Gallatin A, et al. Effects of cyclophosphamide on the development of malignancy and on long-term survival of patients with rheumatoid arthritis. A 20-year follow-up study. Arthritis Rheum 1995;38:1 120-7.

26 Wang CL, Wang F, Bosco JJ. Ovarian failure in oral cyclophosphamide treatment for systemic lupus erythematosus. Lupus 1995:4:11-14.

27 Boumpas DT, Austin HA, Vaughan EM, Yarboro CH, Klippel JH, Balow JE. Risk of sustained amenorrhoea in patients with systemic lupus erythematosus receiving intermittent pulse cyclophosphamide therapy. Ann Intern Med 1993;1 19:366-9.

28 Chan TM, Li FK, Wong RWS, Wong KL, Chan KW, Cheng IKP. Sequential therapy for diffuse proliferative and membranous lupus nephritis: cyclophosphamide and prednisone followed by azathioprine and prednisone. Nephron 1995;71:321-7.

29 Chan TM, Li FK, Tang CS, Wong RWS, Fang GX, Ji YL, et al. Efficacy of mycophenolate mofetil in patients with diffuse proliferative lupus nephritis. Hong Kong-Guangzhou Nephrology Study Group. N Engl J Med 2000;343:1 156-62.

30 Mok CC, Ho CTK, Chan KW, Lau CS, Wong RWS. Outcome and prognostic indicators of diffuse proliferative lupus glomerulonephritis treated with sequential oral cyclophosphamide and azathioprine. Arthritis Rheum 2002;46:1003-13.

31 Sesso R, Monteiro M, Sato E, Kirsztajn G, Silva L, Ajzen H. A controlled trial of pulse cyclophosphamide versus pulse methylprednisolone in severe lupus nephritis. Lupus 1994;3:107-12.

32 Valeri A, Radhakrishnan J, Estes D, D'Agati V, Kopelman R, Pernis A, et al. Intravenous pulse cyclophosphamide treatment of severe lupus nephritis: a prospective five-year study. Clin Nephrol 1994;42:71-8. 
33 Belmont HM Storch M, Buyon J, Abramson S. New York University/Hospital for Joint Diseases experience with intravenous cyclophosphamide treatment: efficacy in steroid unresponsive lupus nephritis. Lupus 1995:4:104-8.

34 Martinelli R, Pereira LJ, Santos ES, Rocha H. Clinical effects of intermittent, intravenous cyclophosphamide in severe systemic lupus erythematosus. Nephron 1996;74:313-17.

35 Conlon PJ, Fischer CA, Levesque MC, Smith SR, St Clair EW, Allen NB, et al. Clinical, biochemical and pathological predictors of poor response to intravenous cyclophosphamide in patients with proliferative lupus nephritis. Clin Nephrol 1996;46:170-5.

36 Korbet SM, Lewis EJ, Schwartz MM, Reichlin M, Evans J, Rohde RD. Factors predictive of outcome in severe lupus nephritis. Lupus Nephritis Collaborative Study Group. Am J Kidney Dis 2000;35:904-14.

37 Ciruelo E, de la Cruz J, Lopez I, Gomez-Reino JJ. Cumulative rate of relapse of lupus nephritis after successful treatment with cyclophosphamide. Arthritis Rheum 1996;39:2028-34.

38 Moroni G, Quaglini S, Maccario M, Banfi G, Ponticelli C. "Nephritic flares" are predictors of bad long-term renal outcome in lupus nephritis. Kidney Int 1996:50:2047-53.

39 Ioannidis JP, Boki KA, Katsorida ME, Drosos AA, Skopouli FN, Boletis $J N$, et al. Remission, relapse, and re-remission of proliferative lupus nephritis treated with cyclophosphamide. Kidney Int 2000;57:258-64.

40 Mok CC, Ying KY, Tang CW, Ng WL, Wong RWS, Lau CS. Role of azathioprine in the prevention of renal relapses after successful cyclophosphamide induction of diffuse proliferative lupus glomerulonephritis [abstract] Arthritis Rheum 2002;46(suppl):S289.

41 Boletis JN, loannidis JP, Boki KA, Moutsopoulos HM. Intravenous immunoglobulin compared with cyclophosphamide for proliferative lupus nephritis. Lancet 1999:354:569-70.

42 Contreras G, Pardo V, Leclercq B, Gomez E, Reich J, O'Nan P, et al. Maintenance therapy for proliferative forms of lupus nephritis: a randomized clinical trial comparing quarterly intravenous cyclophosphamide versus oral mycophenolate mofetil or azathioprine [abstract] J Am Soc Nephrol 2002;13:15A.

43 Bansal VK, Beto JA. Treatment of lupus nephritis: a meta-analysis of clinical trials. Am J Kidney Dis 1997;29:193-9.

44 Boumpas DT, Tassiulas IO, Fleisher TA, Vaughan E, Piscitelli S, Kim Y, et al. A pilot study of low-dose fludarabine in membranous nephropathy refractory to therapy. Clin Nephrol 1999:52:67-75.

45 Davis JC Jr, Austin H 3rd, Boumpas D, Fleisher TA, Yarboro C, Larson A, et al. A pilot study of 2-chloro-2'-deoxyadenosine in the treatment of systemic lupus erythematosus-associated glomerulonephritis. Arthritis Rheum 1998:41:335-43.

46 Lewis EJ, Hunsicker LG, Lan SP, Rohde RD, Lachin JM. A controlled trial of plasmapheresis therapy in severe lupus nephritis. The Lupus Nephritis Collaborative Study Group. N Engl J Med 1992;326:1373-9.

47 Euler HH, Schroeder JO, Harten P, Zeuner RA, Gutschmidt HJ. Treatment-free remission in severe systemic lupus erythematosus following synchronization of plasmapheresis with subsequent pulse cyclophosphamide. Arthritis Rheum 1994;37:1784-94.

48 Wallace DJ, Goldfinger D, Pepkowitz SH, Fichman M, Metzger AL, Schroeder JO, et al. Randomized controlled trial of pulse/ synchronization cyclophosphamide/apheresis for proliferative lupus nephritis. J Clin Apheresis 1998;13:163-6.

49 Danieli MG, Palmieri C, Salvi A, Refe MC, Strusi AS, Danieli G. Synchronized therapy and high-dose cyclophosphamide in proliferative lupus nephritis. J Clin Apheresis 2002;17:72-7.

50 Maloney DG. Preclinical and phase I and II trials of rituximab. Semin Oncol 1999:26(suppl 14):74-8.

51 Perrotta S, Locatelli F, La Manna A, Cennamo L, De Stefano P, Nobili B. Anti-CD20 monoclonal antibody (Rituximab) for life-threatening autoimmune haemolytic anaemia in a patient with systemic lupus erythematosus. Br J Haematol 2002;1 16:465-7.

52 Leandro MJ, Edwards JC, Cambridge G, Ehrenstein MR, Isenberg DA. An open study of $B$ lymphocyte depletion in systemic lupus erythematosus. Arthritis Rheum 2002;46:2673-7.

53 Traynor AE, Schroeder J, Rosa RM, Cheng D, Stefka J, Mujais S, et al. Treatment of severe systemic lupus erythematosus with high-dose chemotherapy and haemopoietic stem-cell transplantation: a phase I study. Lancet 2000;356:701-7.

54 Brodsky RA, Petri M, Smith BD, Seifter EJ, Spivak JL, Styler M, et al. Immunoablative high-dose cyclophosphamide without stem-cell rescue for refractory, severe autoimmune disease. Ann Intern Med $1998 ; 129: 1031-5$

55 Petri M, Jones RJ, Brodsky RA. High-dose cyclophosphamide without stem cell transplantation in systemic lupus erythematosus. Arthritis Rheum 2003;48:166-73.

56 Felson DT, Anderson J. Evidence for the superiority of immunosuppressive drugs and prednisone over prednisone alone in lupus nephritis. Results of a pooled analysis. N Engl J Med 1984;311:152833.
57 Nossent HC, Koldingsnes W. Long-term efficacy of azathioprine treatment for proliferative lupus nephritis. Rheumatology (Oxford) 2000;39:969-74

58 Favre H, Miescher PA, Huang YP, Chatelanat F, Mihatsch M. Cyclosporin in the treatment of lupus nephritis. Am J Nephrol 1989:9(suppl 1):57-60.

59 Tam LS, Li EK, Leung CB, Wong KC, Lai FM, Wang A, et al. Long-term treatment of lupus nephritis with cyclosporin A. Q J Med 1998;91:573-80

60 Fu LW, Yang LY, Chen WP, Lin CY. Clinical efficacy of cyclosporin a neoral in the treatment of paediatric lupus nephritis with heavy proteinuria. Br J Rheumatol 1998;37:217-21.

61 Mok CC, Lai KN. Mycophenolate mofetil in lupus glomerulonephritis. Am J Kidney Dis 2002;40:447-57

62 Karim MY, Alba P, Cuadrado MN, Abbs IC, D'Cruz DP, Khamashta MA, et al. Mycophenolate mofetil for systemic lupus erythematosus refractory to other immunosuppressive agents. Rheumatology (Oxford) 2002:41:876-82.

63 Buratti S, Szer IS, Spencer CH, Bartosh S, Reiff A. Mycophenolate mofetil treatment of severe renal disease in pediatric onset systemic lupus erythematosus. J Rheumatol 2001;28:2103-8.

64 Kingdon EJ, Mclean AG, Psimenou E, Davenport A, Powis SH, Sweny $P$, et al. The safety and efficacy of MMF in lupus nephritis: a pilot study. Lupus 2001;10:606-11.

65 Chan TM, Wong RWS, Lau CS, Tsang EW, Ji YL, Mok MY, et al. Prolonged follow-up of patients with diffuse proliferative lupus nephritis treated with prednisolone and mycophenolate mofetil [abstract] J Am Soc Nephrol 2001;12:A1010.

66 Braun N, Erley C, Klein R, Kotter I, Saal J, Risler T. Immunoadsorption onto protein $\mathrm{A}$ induces remission in severe systemic lupus erythematosus. Nephrol Dial Transplant 2000; 15:1367-72

67 Pfueller B, Wolbart K, Bruns A, Burmester GR, Hiepe F. Successful treatment of patients with systemic lupus erythematosus by immunoadsorption with a Clq column: a pilot study. Arthritis Rheum 2001;44:1962-3

68 Levy Y, Sherer Y, George J, Rovensky J, Lukac J, Rauova L, et al. Intravenous immunoglobulin treatment of lupus nephritis. Semin Arthritis Rheum 2000;29:321-7.

69 Gescuk BD, Davis Jr JC. Novel therapeutic agents for systemic lupus erythematosus. Curr Opin Rheumatol 2002;14:515-21.

70 Finck BK, Linsley PS, Wofsy D. Treatment of murine lupus with CTLA4lg. Science 1994;265:1225-7.

71 Daikh DI, Wofsy D. Cutting edge: reversal of murine lupus nephritis with CTLA4lg and cyclophosphamide. J Immunol 2001;166:2913-16.

72 Daikh DI, Finck BK, Linsley PS, Hollenbaugh D, Wofsy D. Long-term inhibition of murine lupus by brief simultaneous blockade of the B7/CD28 and CD40/gp39 costimulation pathways. J Immunol 1997; 159:3104-8

73 Davis JC Jr, Totoritis MC, Rosenberg J, Sklenar TA, Wofsy D. Phase I clinical trial of a monoclonal antibody against CD40-ligand (IDEC-131) in patients with systemic lupus erythematosus. J Rheumato $2001 ; 28: 95-101$

74 Kalunian KC, Davis JC Jr, Merrill JT, Totoritis MC, Wofsy D; IDEC-131 Lupus Study Group. Treatment of systemic lupus erythematosus by inhibition of T cell costimulation with anti-CD 154: a randomized, double-blind, placebo-controlled trial. Arthritis Rheum 2002;46:3251-8.

75 Jones DS, Barstad PA, Feild M, Hachmann JP, Hayag MS, Hill KW, ef al. Immunospecific reduction of antioligonucleotide antibody-forming cells with a tetrakis-oligonucleotide conjugate (LJP 394), a therapeutic candidate for the treatment of lupus nephritis. J Med Chem 1995; $38: 2138-44$

76 Furie RA, Cash JM, Cronin ME, Katz RS, Weisman MH, Aranow C, et al. Treatment of systemic lupus erythematosus with LJP 394. J Rheumatol $2001 ; 28: 257-65$

77 Alarcon-Segovia D, Tumlin JA, Furie RA, McKay JD, Cardiel MH, Strand V, et al. LJP 394 for the prevention of renal flare in patients with systemic lupus erythematosus: Results from a randomized, double-blind, placebo-controlled study. Arthritis Rheum 2003;48:442-54

78 Wallace DJ. Management of lupus erythematosus: recent insights. Curr Opin Rheumatol 2002;14:212-19.

79 Clark WF, Moist LM. Management of chronic renal insufficiency in lupus nephritis: role of proteinuria, hypertension and dyslipidemia in the progression of renal disease. Lupus 1998;7:649-53

80 Geddes CC, Cattran DC. The treatment of idiopathic membranous nephropathy. Semin Nephrol 2000;20:299-308.

81 Herlitz H, Edeno C, Mulec H, Westberg G, Aurell M. Captopril treatment of hypertension and renal failure in systemic lupus erythematosus. Nephron 1984;38:253-6.

82 Shapira Y, Mor F, Friedler A, Wysenbeek AJ, Weinberger A. Antiproteinuric effect of captopril in a patient with lupus nephritis and intractable nephrotic syndrome. Ann Rheum Dis 1990:49:725-7.

83 Kanda H, Kubo K, Sato K, Tateishi S, Yonezumi A, Yamamoto K, et al. Anti-proteinuric effect of angiotensin II receptor blocker in patients with lupus nephritis [abstract]. Arthritis Rheum 2002;46(suppl):S292. 